\title{
Managerial skills in the globalized world in chosen EU countries
}

\author{
Katarína Čulková1,*, Daniela Hrehová ${ }^{2}$, Andrea Seňová1, and Katarina Teplická ${ }^{1}$ \\ ${ }^{1}$ Technical University of Košice, Faculty BERG, Letná 9, 04002 Košice, Slovakia \\ ${ }^{2}$ Technical University of Košice, Department of Social Science, Letná 9, 04002 Košice, Slovakia
}

\begin{abstract}
Research background: Managerial skills play an increasing role in the globalized world of the business and European Commission is aware of the importance of acquiring and developing a wide range of skills. To solve challenges and problems in business practice, the manager needs to have a wide range of skills in various areas.

Purpose of the article: The contribution is focused on the use of managerial skills in the practice of the selected EU companies. The aim is to find out what managerial skills managers consider important in their practice, which of them they use in the performance of their profession, and how much time they devote to them. Another equally important task of the research is to obtain the necessary data to prepare the necessary training skills for their managers.

Methods: A proven questionnaire survey was used to obtain the necessary data. The target respondents were randomly selected managers at all levels of management with varying degrees of education. The survey is conducted with large number of managers at various levels of the management.

Findings \& Value added: The results of the survey show reserves in managerial skills using in the company and can be used to suggest potential improvements for managers, based on the results of a questionnaire survey. The contribution can be used in the management and development of international business of any company.
\end{abstract}

Keywords: management; skills; EU

JEL Classification: $A 14 ; D 23 ; J 24$

\section{Introduction}

Managerial skills play an important role in the functioning of a company. Managerial skills are acquired through training and practice. They relate to mastering good management practices such as decision making, planning and delegation. Managerial skill is generally defined as the ability of a manager to translate knowledge into practice. Skills are not

\footnotetext{
*Corresponding author: katarina.culkova@tuke.sk
} 
inherent; it is possible to develop them by connecting the educational base, practice, personal experience and inseparable personal preconditions.

To solve challenges and problems in business practice, the manager needs to have a wide range of skills in various areas. The basic prerequisite for success in the field of operation is the necessary technical knowledge. This can be supplemented by the acquisition of interpersonal or communication skills that will ensure the effective use of resources in making managerial decisions.

The contribution deals with managerial skills according to the questionnaire of present state of management in the company, determined for managers at all level of management. From the view of the managerial skills state there is possible to find out reserves and to suggest improvement for effective model of the company management and at the same time to increase effectiveness of skills of all managers in everyday practice.

\section{Present state of problem solving}

Much interest in managerial skills has been generated recently; however, most of the questionnaires on managerial skills have focused on frequency and not competency (Shipper, 1995). Therefore the European Commission is aware of the importance of acquiring and developing a wide range of skills, calling on the Member States of the European Union to promote the full use of human capital through initiatives (Lawrence, 2018). Armstrong (2007) describes in his publication on the latest trends and practices in human resource management that the managerial skills of individual managers, respectively actors of direct management at all levels in the organizational structure, influencing the success of the company presuppose the integrity of processes and procedures for managing these skills. He also suggests that managerial skills should be seen as complex and multifaceted, mental or physical skills, however, it is not enough for the manager to know not only what, but also how and when to use the acquired skills so that they bring the highest possible return in the given conditions of the company (Donnelly et al., 1992).

The professional literature states, resp. uses multiple divisions of managerial skills, as for example Karam (2011) - conceptual, technical and interpersonal skills. Soft skills or interpersonal skills are critical to managerial success. Due to the mentioned Beenen et al. (2018) discussed the need for more rigorous assessment of interpersonal skills. In the frame of managerial skills, managerial coaching has been popularized as a way of motivating, developing and retaining employees in organization), having potential impact on employees. Here Park et al. (2020) identified five dimensions of managerial coaching, demonstrated that managers' utilization of managerial coaching skills had a direct effect on employees' learning and organizational commitment and impacted employees' organizational commitment through personal learning. Zaidi et al. (2021) explain how entrepreneurs initiate their startup business by considering their managerial skills, which could help fast growing economies. According to Ahmad et al. (2021) managerial skills affects strategic planning and performance of small- and medium-sized enterprises (SMEs), indicating the positive effect of managerial skills on SMEs' performance and also suggested that strategic planning mediates the relationship between managerial skills and SMEs' performance and vice versa. In this connection appropriate strategies for SMEs affect the managerial skills on the utilization of the firm's resources. The same is found out yet earlier also by Asah et al. (2015), revealed significant positive relationships between motivations, personal values and managerial skills of SME owners on performance. Similar research as presented contribution is done by Chatterjee and Das (2016), researching five dimensions of skills, namely, leadership skills, communication skills, human relation skills, technical skills and inborn aptitude. It is no secret that employees leave their organizations because of bad managers (Beenen et al., 2021). Organizations should therefore increase interpersonal 
skills to perform well in the managerial role. Despite increasing popularity, little evidence describes the necessity and impact of coaching Carey et al., 2011). Also compassion could be increased among managers through improving their emotional skills (Paakkanen et al., 2020). The importance to study managerial skills is also important from the view of shareholders due to the financial crisis, causing an increase in the risk premium and shareholders' return around the world. In this area Matemilola et al. (2013) investigates the effect of leverage and managerial skills on shareholders' return, finding positive relationships. Except of psychological aspects of managerial skills, also technical aspects are important, providing incremental value to the managerial skill in the managerial performance (Hysong, 2008).

\section{Methodology}

The main goal of the survey was to find out what managerial skills managers consider to be key, which they use in the performance of their profession, and how much time they devote to them on a working day. Another equally important task of the survey was to obtain the necessary data to prepare the necessary training skills for their managers. In order for the corporate culture and employee motivation to be effective, the company's management should know the opinions, attitudes and management methods used by its managers. The survey was conducted through a questionnaire, which was used to obtain the views of a large number of managers at various levels of management in a relatively short time (2 weeks). 96 questionnaires were distributed; the return rate was $92.7 \%$, which represents 89 submitted questionnaires. The questionnaire was anonymous. The necessary data for my diploma thesis were obtained by a questionnaire survey, which is often used as one of the possible quantitative methods. The questionnaire was created in printed form, as it was easier for the company's managers to distribute and collect the questionnaires. In the first part of the questionnaire, the basic data of managers - respondents were ascertained, such as gender, age structure, achieved education of respondents and length of practice of respondents in management as such. In the next part of the questionnaire, their attitudes and experiences in managerial skills were already ascertained. This is an essential part of this questionnaire, which should outline the factual state of managers' skills and on this basis, a training plan should be prepared to improve the necessary practices after the theoretical but also the practical part. The questions were closed, to which the respondents answered by circling the answer that best expressed their opinion. Despite the closed questions, they were able to add a brief comment to their answer. The questionnaires were completed according to the instructions. The questionnaire was created on the basis of the studied theoretical part of this diploma thesis. The questionnaire contains a total of 20 questions focusing on the use of managerial skills. Respondents to these 20 questions also answered basic questions such as age, gender, etc. A questionnaire survey was conducted with the managers of the Bukóza Holding, a.s. at all levels of management with the agreement of the Director-General. The company is located near the town of Vranov nad Toplou. The elaboration and submission of the questionnaires was set for a time horizon of 2 weeks, specifically from 08 June 2020 to 19 June 2020. The answers were collected and evaluated on an ongoing basis. A total of 96 questionnaires were distributed, of which 89 responses were returned. The return of the questionnaire was therefore $92.70 \%$, which is justified by the request for return from the company's management. First, filter questions are evaluated, which classify respondents into individual categories. Furthermore, the questions that are important for meeting the objectives and verifying the established hypothesis of this thesis are evaluated. Among the respondents, men predominated in the number of 77 persons $(86.52 \%)$ and there were 12 female respondents $(13.48 \%)$. This difference is more or less evident because it is an industrial enterprise. Most managers are aged 51-60, which 
represents $40.45 \%$ of all respondents. The second most numerous group of managers is aged $41-50$, which represents $25.84 \%$. The third group of respondents is in the age category of $31-40$ years, which represents $21.35 \%$ of the total number of returned questionnaires addressed to managers. The fourth group of respondents consists of managers aged 60 and over. The least numerous age category of managers is aged 18-30, which is made up of only four respondents, which is $4.49 \%$ of all respondents. Most respondents have completed university education II. degree, which is achieved by the master or engineering degree. 74 people $(83.15 \%)$ achieved this education. The group of respondents with completed secondary school includes 9 persons $(10.11 \%)$. The third group of managers has a university degree with a bachelor's degree. These are 4 managers $(4.49 \%)$, who, however, continue in II. university degree. Highest university education of third degree was achieved by 2 managers $(2.25 \%)$.

\section{Results}

The results had been obtained by requesting and evaluation of the respondents answers according to the following questions:

1. How many years do you act in the management area? With this question, we find out the respondents' practice in management. Managers were required to provide the exact number in an open-ended question. The collected data are grouped into individual categories according to years of managerial experience (see Table 1).

Table 1. The length of the respondents practice in the management.

\begin{tabular}{|c|c|c|}
\hline Possible answer & responds & Rate in \% \\
\hline Less 1 year & 7 & 7.87 \\
\hline 1-5 years & 8 & 8.99 \\
\hline 6-10 years & 11 & 12.6 \\
\hline 11-15 years & 34 & 38.20 \\
\hline 16 and more years & 29 & 32.58 \\
\hline
\end{tabular}

Source: own processing

Table 1 shows that the largest number of managers, namely $34(38.20 \%)$ have 11 to 15 years of experience in management. Another strong group of 29 people $(32.58 \%)$ has been working in management for more than 16 years. 11 managers $(12.36 \%)$ have experience in the field of management in the range of $6-10$ years. A total of 15 managers (16.86\%) have experience in management for a maximum of 5 years, including those within one year.

2. Do you know how to use managerial skills in the practice? The question found out effective using of managerial skills during performance of the working position, the results is illustrated by Table 2 .

Table 2. Effectiveness of managerial skills using in the practice.

\begin{tabular}{|c|c|c|}
\hline Possible answer & responds & Rate in \% \\
\hline Yes - regularly & 18 & 20.22 \\
\hline Yes - irregularly & 43 & 48.31 \\
\hline No - but trying & 25 & 28.10 \\
\hline No - I do not need it & 3 & 3.37 \\
\hline
\end{tabular}

Source: own processing

It is clear from Table 2 that not all managers effectively use managerial skills as a management tool. 43 managers (48.31\%) stated that they use these skills but not regularly. In the second group of managers who have an effort but do not use managerial skills in 
practice, there are up to 25 people $(28.10 \%)$ of the total number of managers who submitted questionnaires. That's pretty much more than a quarter of management. The question here is whether these are the right people in the right place. It is quite shocking that 3 managers answered that they do not need to use these skills in their practice. Only 18 managers $(20.22 \%)$ use managerial skills regularly and we assume that they are effective. When creating the possibilities of answers, we thought that we would not find anyone in the last group. This is definitely an area for reflection for the whole society.

3. How often do you use communication skills in your work? The question gives answer to the time of communication skills using in the practice of the managers work in the company. The answers are given in Table 3.

Table 3. Time spent by manager for the communication.

\begin{tabular}{|c|c|c|}
\hline Possible answer & responds & Rate in \% \\
\hline Daily & 78 & 87.64 \\
\hline 3 times per week & 7 & 7.87 \\
\hline Once a week & 4 & 4.49 \\
\hline Two times per month & 0 & 0.00 \\
\hline Never & 0 & 0.00 \\
\hline
\end{tabular}

Source: own processing

Table 3 shows that communication as a managerial skill is used by managers at different times during the working day. Most managers 78 (87.64\%) wrote that they actively communicate with their subordinates, resp. other employees during their working hours. The second group of 11 correspondents together (12.36\%) communicates with colleagues resp. subordinates approximately 1-3 per week. Thus, it is generally possible to state that the respondents actively communicate almost during the whole working day. There is no manager at any level in the company who would not be able to communicate at the appropriate level.

4. What is the frequency of the delegation skills using? The question gives idea of managers 'skills to delegate working task to the subordinates.

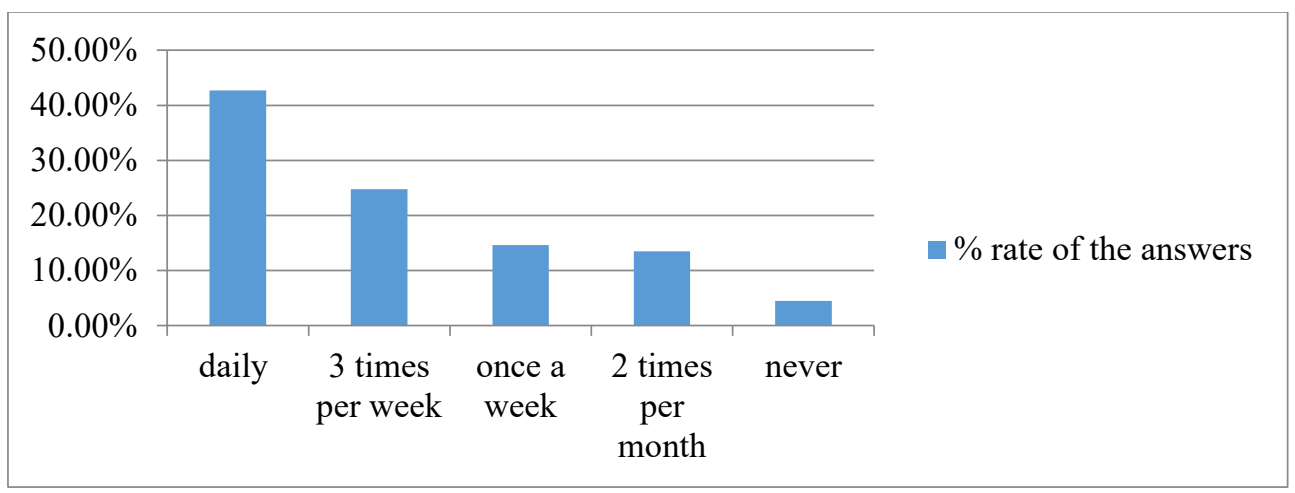

Figure 1. Frequency of the delegation skills using.

Source: own processing

According to the Figure 1 we can say that 38 respondents $(42,7 \%)$ delegate tasks every day. 22 managers $(24,72 \%)$ mentioned they delegate the tasks three times per week. Approximately once a week delegate 13 managers (14,61\%). Yet 12 respondents $(13,48 \%)$ speak of delegation only two times per month. Only 2 managers $(4,49 \%)$ delegate never. Here is the question if such managers are at the proper place when they do not delegate, it means, they do not know how to manage. 
5. What is the frequency of the coaching in your practice? The answers are given in table 4.

Table 4. Frequency of coaching using in managerial practice.

\begin{tabular}{|c|c|c|}
\hline Possible answer & Responds & Rate in \% \\
\hline Daily & 7 & 7.87 \\
\hline 3 times per week & 15 & 16.85 \\
\hline Once a week & 22 & 27.72 \\
\hline 2 times per month & 31 & 34.83 \\
\hline never & 14 & 15.73 \\
\hline
\end{tabular}

Source: own processing

Table 4 expresses that 31 respondents $(34.84 \%)$ can coach some of their subordinates about twice a week within their working hours and duties. 22 respondents $(24.72 \%)$ coach their subordinates about once a week. 15 managers (16.85\%) stated that they are able to coach their subordinates about 3 times a week. He can coach his subordinates 7 managers on a daily basis $(7.87 \%)$. It is surprising that up to 14 managers $(15.73 \%)$ do not coach their subordinates at all. It is to the detriment of things, because in this way the managerial skills stagnate and the experience is not passed on to other employees.

6. What is the frequency of decision skills using in your practice? The question gives idea of coaching ability of the managers in the frame of his working activities.

Figure 3 expresses that 52 respondents (58.43\%) make decisions on a daily basis within their working hours and duties. At least 3 times a week, 22 respondents - managers (24.72\%) make decisions. 11 respondents (12.36\%) make decisions at their level about once week. 4 respondents $(4.49 \%)$ stated that they make decisions at their level about twice a month. It follows from the above that there is no manager in the company in question who would never make a decision. If that were the case, it would be more than non-standard.

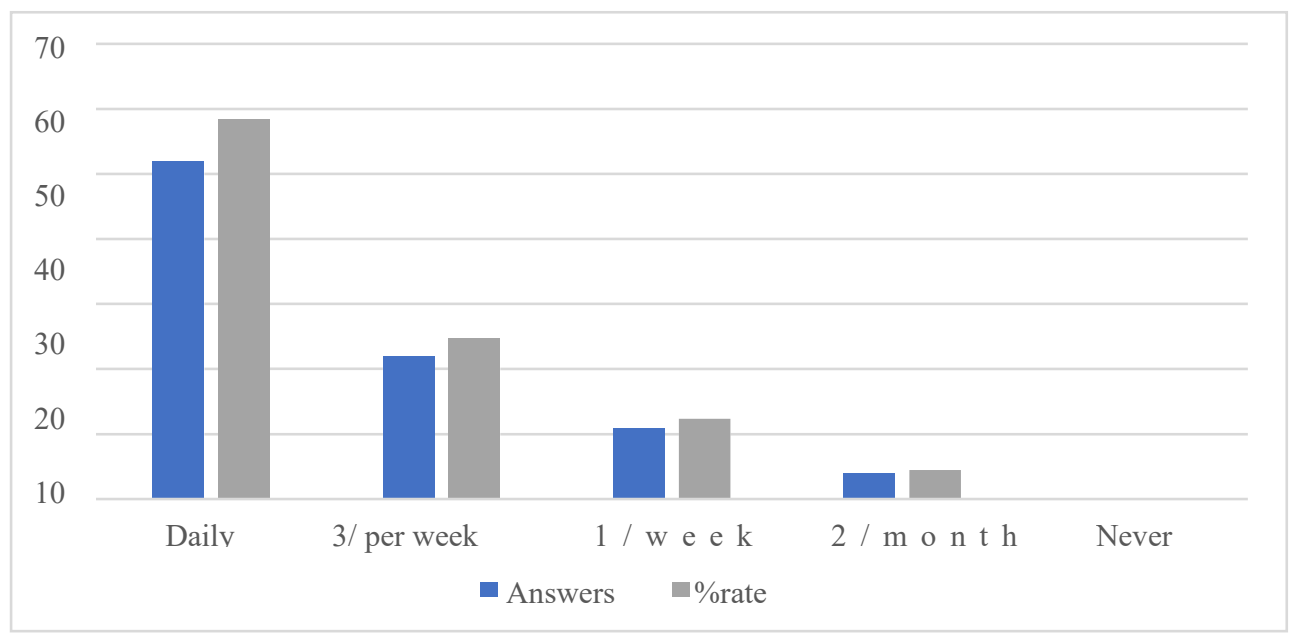

Figure 2. Frequency of decision skills using in the managerial practice.

Source: own processing

7. What is the frequency of the negotiation skills in your practice? The question gives idea of the manager to negotiate with his subordinates. 


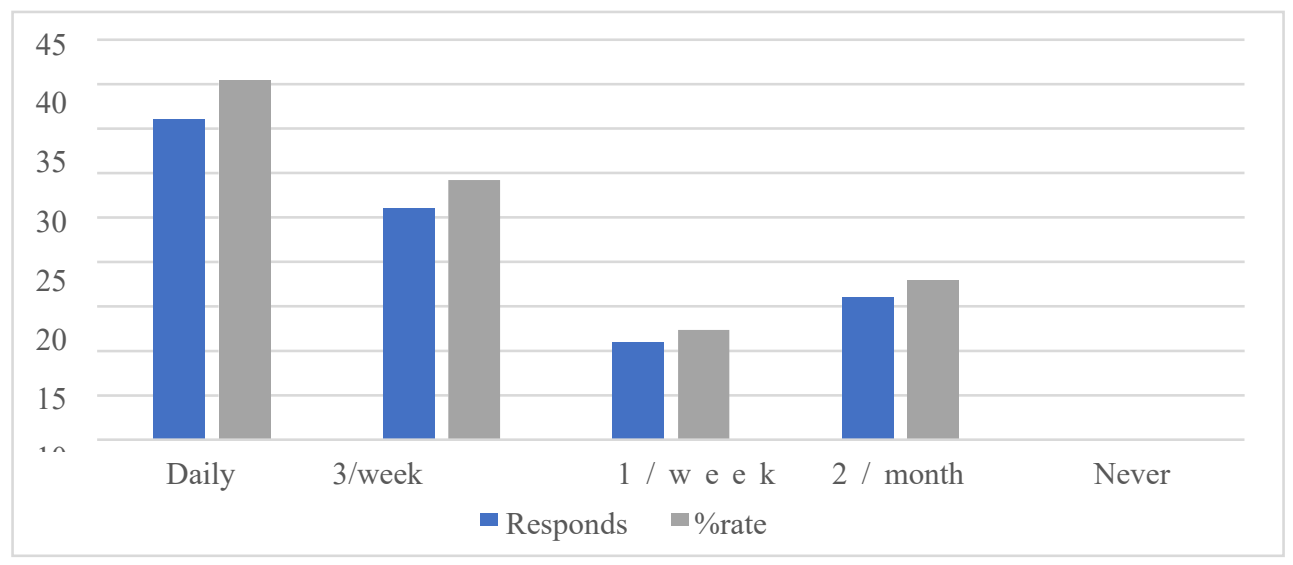

Figure 3. Frequency of negotiation skills using in managerial practice.

Source: own processing

Thanks to Figure 3, it can be stated that the use of negotiation in practice is variable. 36 managers $(40.45 \%)$ say that they negotiate on a daily basis and 26 managers $(29.21 \%)$ indicated that they negotiate about 3 times a week. Another 16 respondents (17.98\%) say that they negotiate about twice a month. 11 respondents $(12.36 \%)$ indicated that it is enough to negotiate once a week. Our questionnaire did not find a respondent - a manager who does not negotiate at all in his practice.

8. What is the frequency of team workshops using in your work? The answers give idea of manager's skills to participate at the team workshops. Table 5 shows that most managers, namely $42(47.19 \%)$, need to attend a team meeting at least once a week. Another 21 respondents $(23.60 \%)$ said that team meetings are held on average 2 times a month, which is every other week. 13 respondents $(14.61 \%)$ prefer to participate in a team meeting on a daily basis. 9 respondents $(10.11 \%)$ participate in a team meeting about 3 times a week. Only 4 managers $(4.49 \%)$ indicated that they do not have team meetings at all.

Table 5. Frequency of team workshops using in the managerial practice.

\begin{tabular}{|c|c|c|}
\hline Possible answers & Responds & \% rate \\
\hline Daily & 13 & 14.61 \\
\hline 3 times per week & 9 & 10.11 \\
\hline Once a week & 42 & 47.19 \\
\hline 2 times per month & 21 & 23.60 \\
\hline Never & 4 & 4.49 \\
\hline
\end{tabular}

Source: own processing

9. What is the frequency of time management using in your practice? The question provides responds to ability of the manager use the time in his working activities.

Table 6. Frequency of time management in the managerial practice.

\begin{tabular}{|c|c|c|}
\hline Possible answers & Responds & \% rate \\
\hline Daily & 42 & 47.19 \\
\hline 3 times per week & 21 & 23.60 \\
\hline Once a week & 12 & 13.48 \\
\hline 2 times per month & 10 & 11.24 \\
\hline Never & 4 & 4.49 \\
\hline
\end{tabular}


Source: own processing

Table 6 shows the information that 42 respondents $(47.19 \%)$ plan their time on a daily basis. 21 managers $(23.60 \%)$ plan their time about 3 times a week. 12 respondents $(13.48 \%)$ manage their time once a week. 10 managers $(11.24 \%)$ indicated that they only manage time 2 times a month. The remaining 4 respondents $(4.49 \%)$ state that they do not use time management in practice at all.

10. What is the frequency of control activity using in your work? The answers speak about the ability of the manager to control tasks solving of the subordinates.

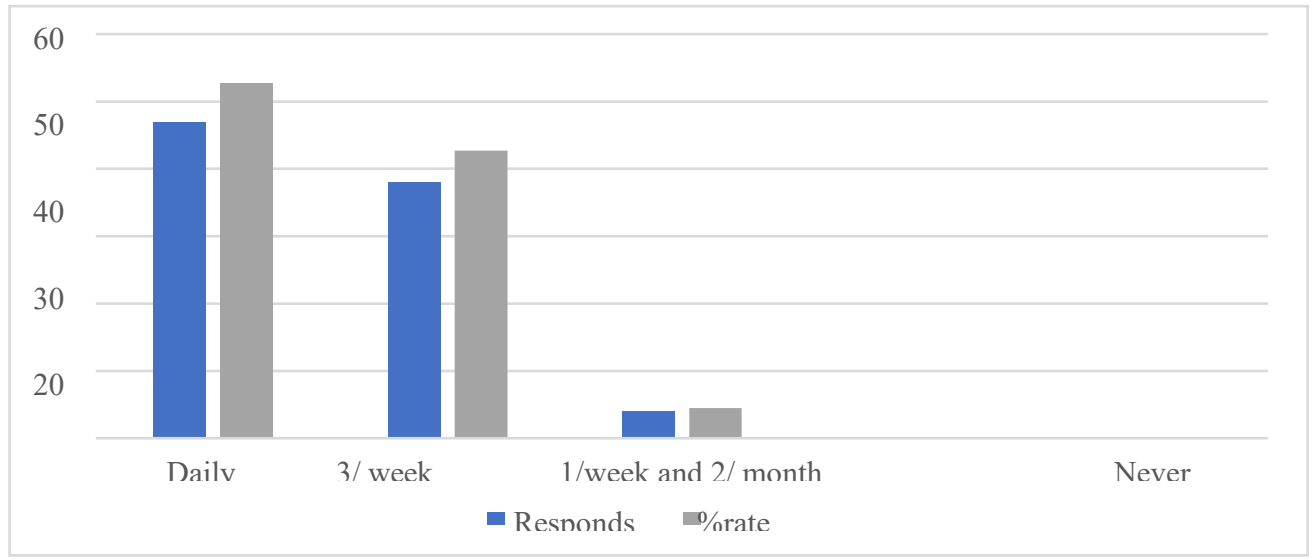

Figure 4. Frequency of the control using in the managerial practice.

Source: own processing

From Figure No. 4 it is clear that the control activities give managers great importance, because up to 47 respondents (52.81\%) perform the control of planned or assigned tasks, respectively. processes on a daily basis and another 38 respondents $(42.70 \%)$ deal with the control approximately 3 times a week. Only 4 respondents only need to perform control activities once a week. There is no manager in the interviewed company who would not use this managerial skill in his practice.

11. What is the space for the creativity in your work? The managerial skills can be evaluated also according to the creative thinking of the managers. The responds are given by table 7 .

Table 7. Using of creativity in the managerial practice

\begin{tabular}{|c|c|c|}
\hline Possible answer & Responds & \% rate \\
\hline Not limited & 14 & 15.73 \\
\hline According to the situation & 53 & 59.55 \\
\hline Sometimes & 22 & 24.72 \\
\hline Any & 0 & 0.00 \\
\hline
\end{tabular}

Source: own processing

\section{Discussions and Conclusions}

Based on a questionnaire survey, which was conducted with managers of all levels of management of the group of companies Bukóza Holding, a.s. we obtained information on the basis of which we came to several findings, which I want to use in this chapter to make recommendations and possible changes in the practice of managers. I will always rely only on the submitted questionnaires. The questionnaire finding regarding time management is 
not at all satisfactory. In managerial practice, it is almost unacceptable for managers at any management level to state that they have not used the principles of managing their working time on a daily basis. The results of the questionnaire survey show that time management managers use it most often on a daily basis, but several managers also stated that they rarely plan their time at work. It is astonishing that 4 managers stated in the questionnaire that they do not use time management at all. We recommend certified training in this area, where managers would find that by managing their time well, they would be able to perform many times more activities and relieve the stress of time pressure or the chaos of not organizing activities. We also recommend that inexperienced managers could be coached in the skill in question by more experienced managers, and thus teach every skill manager how to plan their working hours. The manager should acquire the ability to plan his time already during his studies at high school or university, and after starting his education they should give him the opportunity to develop this skill in managerial practice. By the way, about half of the respondents are involved in active coaching for at least one week, so the improvement of this skill in the surveyed company would also be used.

Team meetings are the best way to improve the level of managerial skills within the company. Meetings of colleagues in the work should serve not only to solve problems and submit proposals for the organization itself. Team meetings are also teamwork because more managers meet and are equal during it. We recommend that at least one day a week during the meeting, managers deal with various model situations and learn from each other how best to handle these situations. Managers would be able to improve other skills, such as communication, negotiation and peer feedback could help many to make the right decisions. From the evaluation of the questionnaire, it is clear that managers carry out control activities very often. If we take into account the proverb that trust and verify, then that's fine. However, we recommend setting up control mechanisms in the company so that this activity does not take up much space in managerial activities unnecessarily. In terms of the use of task delegation, company managers are aware that they should manage at their levels and not solve everything. Thus, the delegation of tasks is at an optimal level. When we consider the answers to the questions about the importance and frequency of using individual managerial skills, we see that many managers stated that the use of innovative solutions and creative thinking is at a very low level. It reaches only $1 / 3$ of the surveyed managers. Therefore, we state that managers are not sufficiently educated in the field of innovation. We recommend training key managers in innovation and investment.

\section{Acknowledgements}

Contribution is partial result of projects solving KEGA No 049TUKE-4/2019 and KEGA 006TUKE-4/2019.

\section{References}

1. Ahmad, I., \& Ahmad, S. B. (2021). Effect of managerial skills on the performance of small and medium sized enterprises: A case study in Pakistan. Journal of Asian finance economics and business, 8(4), 161-170.

2. Armstrong, M. (2007). Řizení lidských zdrojů - Nejnovějši trendy a postupy. Praha: GradaPublishing, a.s., 800.

3. Asah, F., Fatoki, O. O., \& Rungani, E. (2015). The impact of motivations, personal values and management skills on the performance of SMEs in South Africa. African Journal of Economic and Management Studies, 6(3), 308-322. 
4. Beenen, G., Pichler, S., \& Davoudpour, S. (2018). Interpersonal skills in MBA admissions: How are they conceptualized and assessed? Journal of Management education, 42(1), 34-54.

5. Beenen, G., Pichler, S., Livingston, B., \& Riggio, R. (2021). The good manager: Development and validation of the managerial interpersonal skills scale. Frontiers in Psychology, 12, Art. No 631390.

6. Carey, W., Philippon, D. J., \& Cummings, G. G. (2011). Coaching models for leadership development: An integrative review. Journal of Leadership Studies, 5(1), 51-69.

7. Chatterjee, N., \& Das, N. (2016). A study on the impact of key entrepreneurial skills on business success of Indian micro-entrepreneurs: A case of Jharkhand region. Global Business Review, 17(1), 226-237.

8. Donnelly, J. H., Gibson, J. L., \& Ivancevich, J. M. (1992). Fundamentals of management. Boston: Irwin, 358.

9. Európska komisia prijala nový program v oblasti zručností pre Európu (2016). https://www.minedu.sk/europska-komisia-prijala-novy-program-v- oblasti-zrucnostipre-europu/.

10. Hysong, S. J. (2008). The role of technical skill in perceptions of managerial performance. Journal of Management Development, 27(3), 275-290.

11. Karam, P. (2011). Management Concepts and Organizational Behaviour. New Delhi: I.K.International House Pvt. Ltd, 528.

12. Lawrence, J. (2018). Introduction to Business. Rice University: OpenStax, 2018. 703.

13. Matemilola, B. T., Bany-Ariffin, A. N., \& Azman-Saini, W. N. W. (2013). Impact of leverage and managerial skills on shareholders'return. International Conference on Economics and Business Research, 7, 103-115.

14. Paakkanen, M., Martela, F., Hakanen, J., Uusitalo, L., \& Pessi, A. (2020). Awakening compassion in managers - A new emotional skills intervention to improve managerial compassion. Journal of Business and Psychology.

15. Park, S., McLean, G. N., \& Yang, B. Y. (2020). Impact of managerial coaching skills on employee commitment: The role of personal learning. European Journal of Training and Develoment.

16. Shipper, F. (1995). A study of the psychometric properties of the managerial skill scales of the survey of management-practices. Educational and Psychological Measurement, 55(3), 468-479.

17. What Makes G Great (2020). https://www.nytimes.com/2020/05/06/learning/what-makes-a-great-leader.html.

18. Zaidi, R. A., Khan, M. M., Khan, R. A., \& Mujtaba, B. G. (2020). Do entrepreneurship ecosystem and managerial skills contribute to startup development? South Asian Journal of Business Studies. 